\title{
Children's response alternation as a function of stimulus duration, intertrial interval, and trials'
}

\author{
WILLIAM L. CROLL \\ UNIVERSITY OF IOWA
}

On each of a series of trials preschool children were required to make one of two responses, thus activating one of two stimuli. The relative frequency of response alternation decreased across trials, but did not vary with the stimulus duration or intertrial interval length. Response latency did not vary with stimulus duration, intertrial interval, or trials. Sequential response dependencies were examined.

Children's response alternation has been shown to be a function of stimulus variability (Ellis \& Arnoult, 1965) and of the child's "curicsity" level (Peters \& Penney, 1966). The present study investigates the relative frequency of children's response alternation as a function of stimulus duration (STD), intertrial interval (ITI) length, and trials. Hull's (1943) reactive inhibition $\left(I_{R}\right)$ model and Glanzer's (1953) stimulus satiation ( $I_{S}$ ) model were used to generate predictions for the present experiment.

Method

The Ss were 30 four and five year old children from the University of Iowa Preschools. The apparatus consisted of a black stimulus panel upon which two stimulus lights were located in left-right orientation. Each light was $12 \mathrm{in.} \mathrm{high} \mathrm{and} \mathrm{5-1/2} \mathrm{in.} \mathrm{wide.} \mathrm{The} \mathrm{distance} \mathrm{between}$ the lights was $3-1 / 2$ in. Two in. below the center of the lower edge of each light was a response button. The left button, when pressed, activated the left light, and the right button activated the right light. Both lights appeared white when not activated.

For each $S$ one light appeared pink $(P)$ when activated and the other light appeared yellow (Y) when activated. For a random half of Ss the left light was $P$, while for the remaining Ss the right light was $P$. The left button was the same color as the left light and the right button was the same color as the right light.

Each S was brought individually to the semi-darkened experimental room and was seated in front of the stimulus panel. The $\mathrm{E}$ sat behind $\mathrm{S}$. The $\mathrm{S}$ was told that on each trial he was to press one of the buttons and watch the light which came on. He was told that on each trial he could press either button. The S pressed the buttons with his right hand. When he was not responding he kept his hand on a marker equidistant from the two buttons.

Each trial began with $\mathrm{E}$ saying "push." The $\mathrm{S}$ then pushed one of the buttons, thus activating one of the lights. The duration of the light (STD) was 3,6 , or 9 sec. Offset of the light began the ITI which was also 3,6 , or 9 sec. Each $S$ received 10 trials under each of the nine possible STD-ITI combinations. Since the response on trial $\mathrm{n}$ was being studied as a function of the STD and ITI on trial n-1, a 91st trial was given to assess the effect of the STD and ITI used on trial 90. The order of occurrence of STD-ITI combinations was random, with the restriction that exactly five of each of the nine STD-ITI combinations occur in both the first 45 trials and the second 45 trials. A different random order was used for each $S$. On each trial $E$ recorded $S^{\prime}$ 's choice response ( $P$ or $Y$ ) and the response latency. Resulis

The relative frequency of response alternation was computed for trials following each of the nine different STD-ITI combinations. This was done for each of two blocks of 45 trials for each $S$. These scores were entered into an extended $A$ by $B$ by Sanalysis of variance (Lindquist, 1953). The three treatments in this analysis, all of which were within-Ss treatments, were STD, ITI, and trial blocks. The only effect significant at the .05 level was that of trial blocks. The relative frequency of alternation was greater in the first block (.641) than in the second block (.431).

The mean response latency was computed for trials following each of the nine different STD-ITI combinations. These scores were entered into an analysis of variance identical to that performed on the alternation data. There were no significant effects. Thus, response latency did not vary as a function of ITI, STD, or trial blocks. The mean response latency was $2.39 \mathrm{sec}$.

Sequential response dependencies were obtained. Table 1 shows the observed relative frequencies estimating selected sequential response probabilities. An entry in the left column of this table of the form $\operatorname{Pr}(x \mid y)$, where $x$ and $y$ represent $P$ or $Y$, denotes the conditional probability of observing response $x$ on trial $n$, given that response $y$ occurred on trial $n-1$. Simi-

Table 1. Sequential Response Dependencies

\begin{tabular}{lcc} 
Probability & \multicolumn{2}{c}{ Observed Relative Frequency } \\
Block 1 & Block 2 \\
\hline $\operatorname{Pr}(P \mid P P)$ & .569 & .791 \\
$\operatorname{Pr}(P \mid P Y)$ & .332 & .373 \\
$\operatorname{Pr}(P \mid Y P)$ & .700 & .559 \\
$\operatorname{Pr}(P \mid Y Y)$ & .540 & .356 \\
$\operatorname{Pr}(Y \mid P P)$ & .431 & .209 \\
$\operatorname{Pr}(Y \mid P Y)$ & .668 & .627 \\
$\operatorname{Pr}(Y \mid Y Y)$ & .460 & .644 \\
$\operatorname{Pr}(Y \mid Y P)$ & .300 & .441 \\
$\operatorname{Pr}(P \mid P)$ & .420 & .586 \\
$\operatorname{Pr}(P \mid Y)$ & .649 & .462 \\
$\operatorname{Pr}(Y \mid P)$ & .580 & .414 \\
$\operatorname{Pr}(Y \mid Y)$ & .351 & .538 \\
$\operatorname{Pr}(P)$ & .527 & .527 \\
$\operatorname{Pr}(Y)$ & .473 & .473 \\
\hline
\end{tabular}


1arly, $\operatorname{Pr}(x \mid y z)$, where $x, y$, and $z$ represent $P$ or $Y$, denotes the conditional probability of observing response $x$ on trial $n$, given that response $y$ occurred on trial n-1 and that response $z$ occurred on trial n-2. Discussion

Glanzer (1953) states that both the $I_{R}$ and $I_{S}$ models predict a decrease in alternation across trials. This prediction was supported since the relative frequency of alternation was greater in the first block of trials than in the second block of trials. The $I_{R}$ model predicts the frequency of alternation to be a decreasing function of STD, while the $\mathrm{I}_{\mathrm{S}}$ model predicts an increasing function. Neither model was supported, since alternation was observed to be a constant function of STD. Both models predict alternation to be a decreasing function of ITI length. This prediction was not supported since alternation was observed to be a constant function of ITI.

Both models make the same predictions for sequential response dependencies. These predictions are $\operatorname{Pr}(x \mid x x)$ $<\operatorname{Pr}(\mathbf{x} \mid \mathbf{x})<\operatorname{Pr}(\mathrm{x})$, where $\mathrm{x}$ represents $\mathrm{P}$ or $\mathrm{Y}$. As can be seen from Table 1 , these predictions were not supported. In fact, the observed rank orders for Block 2 were exactly the opposite of those predicted, thus making it seem unlikely that $I_{R}$ or $I_{S}$ accounts for the behavior under consideration. Table 1 also indicates that $\operatorname{Pr}(P \mid Y)$ and $\operatorname{Pr}(Y \mid P)$ both decrease across trial blocks. This result simply reflects the previously mentioned decrease in alternation across trial blocks.

\section{References}

Ellis, N. C., \& Amoult, M. D. Novelty as a determinant of spontaneous alternation in children. Psychon. Sci., 1965, 2, 163-164.

Glanzer, M. Stimulus satiation: An explanation of spontaneous alternation and related phenomena. Psychol. Rev., 1953, 60, 257268.

Hull, C. L. Principles of behavior. New York: Appleton-CenturyCrofts, 1943.

Lindquist, E. F. Design and analysis of experiments in psychology and education. Boston: Houghton Mifflin Co., 1953.

Peters, R. D., \& Penney, R. K. Spontaneous alternation of high and low reactively curious children. Psychon. Sci., 1966, 4, 139-140.

\section{Note}

1. This paper is based on a thesis submitted in partial fulfillment of the requirements for the degree of Master of Arts, in the Institute of Child Behavior and Development, in the Graduate College of the University of Iowa. The writer is indebted to Professor Richard S. Bogartz for his advice and assistance. 